\title{
A Comparison of Frictional Resistance between Active and Passive Self-ligating Brackets with Conventional Bracket Systems
}

\author{
${ }^{1} \mathrm{H}$ Jyothikiran, ${ }^{2}$ Sachin Bansal, ${ }^{3}$ Azeem Farhan, ${ }^{4}$ Shivalinga BM \\ ${ }^{1}$ Associate Professor, Department of Orthodontics and Dentofacial Orthopedics, JSS Dental College and Hospital, Mysore, Karnataka, India \\ ${ }^{2}$ Former Postgraduate Student, Department of Orthodontics and Dentofacial Orthopedics, JSS Dental College and Hospital \\ Mysore, Karnataka, India \\ ${ }^{3}$ Professor, Department of Orthodontics and Dentofacial Orthopedics, Vydehi Dental College, Bengaluru, Karnataka, India \\ ${ }^{4}$ Professor and Incharge of Postgraduate Studies, Department of Orthodontics and Dentofacial Orthopedics, JSS Dental College and \\ Hospital, Mysore, Karnataka, India
}

Correspondence: H Jyothikiran, Associate Professor, Department of Orthodontics and Dentofacial Orthopedics, JSS Dental College and Hospital, Mysore, Karnataka, India, Phone: +91 9448163485, e-mail: drjyothikiran8874@gmail.com

\section{ABSTRACT}

Friction, though, is an inseparable and undeniable orthodontic entity that should be minimized, if not eliminated, for obtaining an optimal biological tissue response.

Aim: The present study compared the frictional resistance of active (time- 2, In-Ovation R) and passive (Damon SL-2, Smart clip) self-ligating brackets with conventional titanium, fiberglass and ceramic brackets under dry and wet conditions with artificial saliva using universal testing machine.

Methods: Modified Tidy's jig was constructed to simulate clinical situation. A total of 200 samples were tested. Specimens were divided into two categories which were run under dry and wet conditions, using artificial saliva. Around 10 samples of each active and passive selfligating brackets were dry run and 10 others were used in wet conditions. Around 10 samples of each ceramic, titanium and fiberglass brackets were run using elastomeric ties in both dry and wet conditions and 10 each of them using stainless steel ligatures under dry and wet conditions.

Results: The study revealed that the least frictional resistance was demonstrated by the brackets in the following order, i.e. passive selfligating brackets, active self-ligating brackets, titanium, fiberglass and ceramic brackets in both dry and wet conditions.

Conclusion: The self-ligating brackets seem to be promising in quenching the thirst of orthodontist to have a bracket that is functionally efficient with reduced friction, esthetically pleasing, reduced treatment and chairside time, combined with better oral hygiene maintenance and patient comfort because of absence of ligation.

Keywords: Active and passive self-ligating brackets, Conventional brackets, Frictional resistance.

\section{INTRODUCTION}

Since advent of fire by stone aged man, the virtues of friction have been bestowed upon mankind; sometimes as a hindrance and at other times... as a boon!!!

Friction is an inseparable and undeniable orthodontic entity and has been documented in orthodontic literature by Stoner as far back as $1960{ }^{1}$

During tooth movement, it is crucial that frictional forces be minimized, if not eliminated, to apply an appropriate force for obtaining an optimal biologic tissue response for efficient and desired tooth movement... the ultimate goal in clinical orthodontics!

Availability of wide array of brackets, wires and ligatures has provided the clinician, a multitude of combinations for use during various stages of orthodontic treatment.

In the workhouse of sliding mechanics, the bracket material of choice for many years has been stainless steel for its many desirable properties like high fracture resistance, lesser friction and cost-effectiveness.
But concern was expressed regarding nickel hypersensitivity and corrosion in the oral environment. ${ }^{2}$

To bridge this gap, pure titanium brackets have been made available (by Dentaurum, Germany).

Titanium — a material whose biocompatibility has been demonstrated beyond doubt.

Titanium has been heralded as a material totally biocompatible in the oral environment and superior in structural integrity compared to stainless steel. ${ }^{3}$

However, since the number of adult patients has been steadily increasing, the esthetic ceramic material was made available. Though ceramic had excellent color fidelity and stain resistance, it had shortcomings, such as fracture of enamel during debonding and of the bracket itself, high friction and enamel abrasion of the opposing tooth. ${ }^{4}$

To rectify these shortcomings, fiber glass brackets were introduced...but had shortcomings in frictional factor.

Though brackets were esthetically and functionally efficient, nothing eliminated the mode of ligation... which increased the 
friction factor, chairside time and compromise on oral hygiene maintenance and patient comfort.

To quench this thirst, had come the self-ligating brackets, which were efficient functionally, pleasing esthetically, reduced treatment and chairside time combined with patient comfort and better oral hygiene maintenance because of absence of ligation.

The present study was undertaken to compare all these brackets for their frictional resistance in dry and wet conditions along with higher magnification to confirm slot surface topography under SEM.

\section{MATERIALS AND METHODS}

\section{Materials}

$\left.\left.\begin{array}{l}\text { SS self-ligating } \\ \text { Passive brackets }\end{array}\right\} \begin{array}{l}\text { Damon SL-2 (Fig. 1) } \\ \text { Smart clip (Fig. 2) } \\ \text { SS self-ligating } \\ \text { Active brackets }\end{array}\right\} \begin{aligned} & \text { Time-2 (Fig. 3) } \\ & \text { In-Ovation R (Fig. 4) }\end{aligned}$

Titanium brackets Rematitan (Fig. 5)

Fiberglass

brackets

DB Fiberglass

Ceramic brackets Fascination (Fig. 7)

Elastomeric Sanities

modules

Straight shooter (Fig. 8)

wires

$$
19 \times 25 \text { SS }
$$

Remanium

Artificial saliva

modified

Tidy's jig

Trans bond XT

(Fig. 9)

Light cure adhesive

3M Unitek

SDC California, Ormco

3M Unitek

American

Ortho, USA

GAC, New York

Dentaurum, Germany Leone, Italy

Dentaurum, Germany GAC, New York TP-Orthodontics Dentaurum, Germany

In this study, conventional brackets were chosen to compare with active and passive self-ligating brackets.

All brackets used in the study were maxillary right cuspid's of $0.022^{\prime \prime}$ slot dimension with angulations of $13^{\circ}$ and torque of $-2^{\circ}$ (Roth version)

Specimens were assorted at JSS Dental College and Hospital, Mysore, Karnataka, India, and tests were carried out at CIPET (Central Institute of Plastics and Engineering Technology), Mysore, Karnataka, India.

SEM specimens were viewed at magnification of X500 at $20 \mathrm{kV}$ (Figs 10A to D). SEM was recorded for each bracket type to compare slot surface texture.

Modified Tidy's jig was constructed to simulate clinical situation. The device consisted of stainless steel framework with $15 \mathrm{~mm}$ space for movable bracket at the center. Archwires were secured with hex screws using Allen keys.

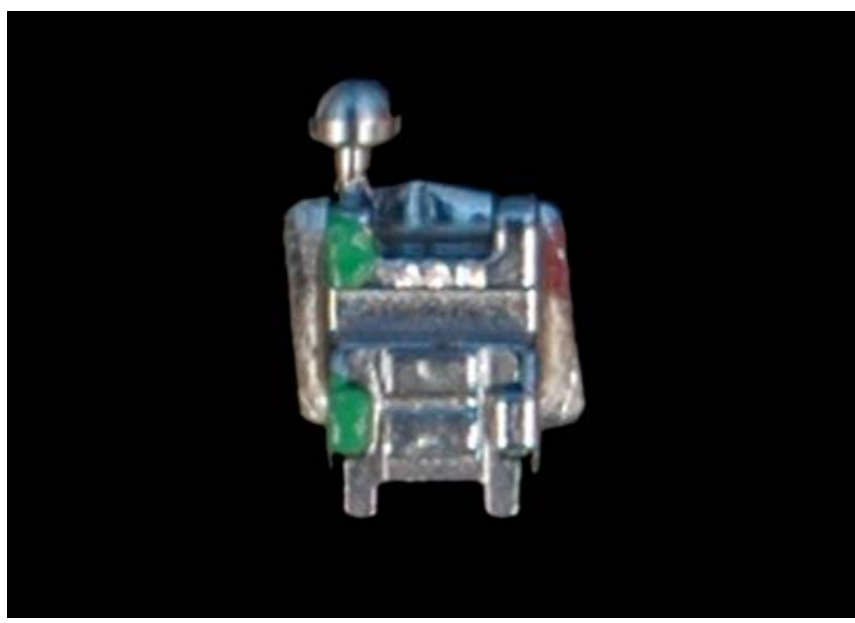

Fig. 1: Damon SL 2

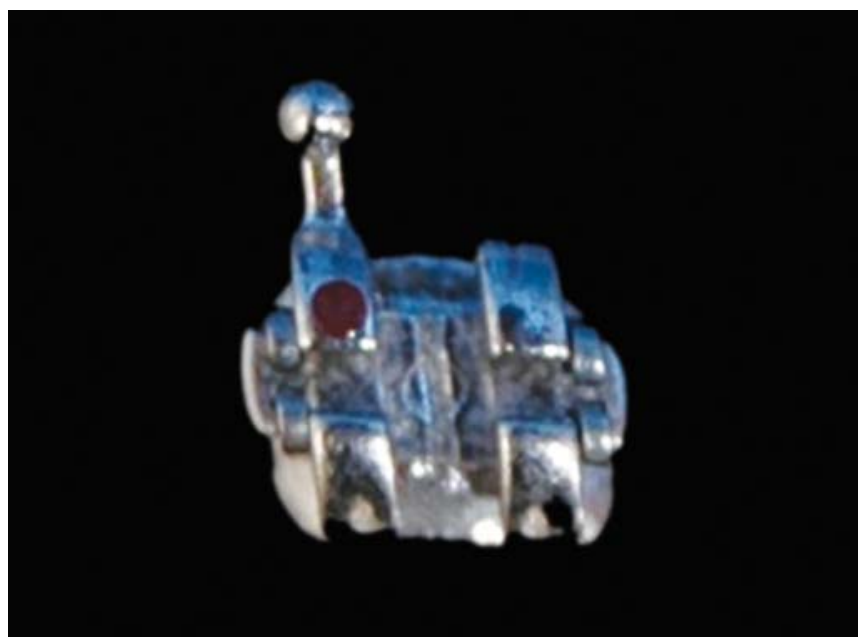

Fig. 2: Smart clip

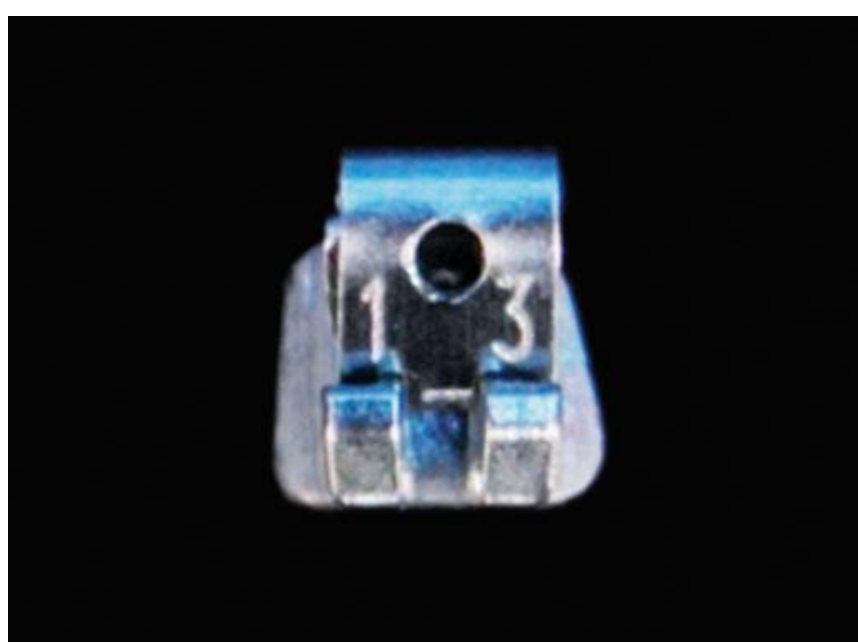

Fig. 3: Time II

Additional power arm of $12 \mathrm{~mm}$ was chosen to represent the distance from bracket slot to the center of resistance of a typical canine tooth, which was bonded to the base of the bracket using transbond-XT from which the weights could be suspended.

A fixed weight of $100 \mathrm{gm}$ (representing normal force) was suspended from the additional power arm. 


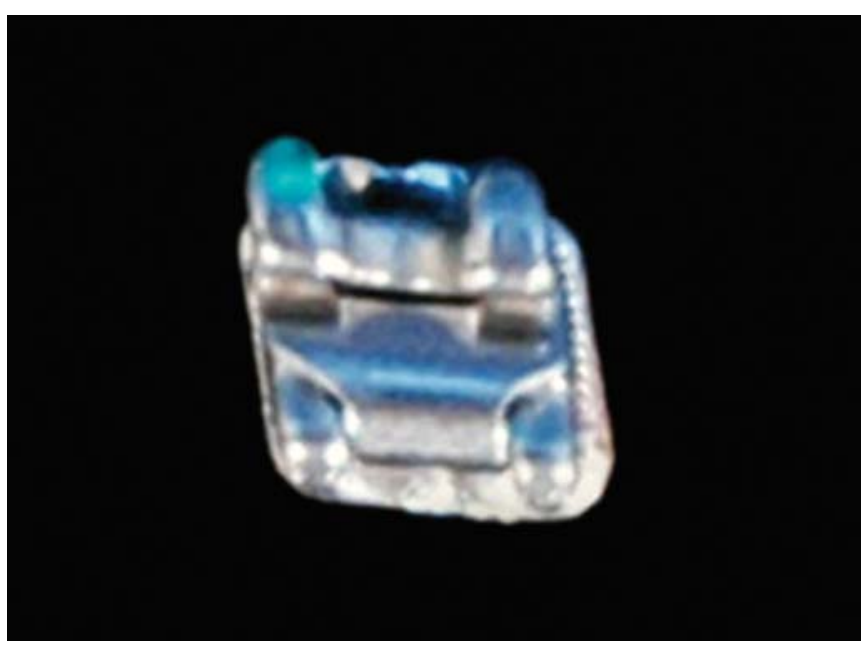

Fig. 4: In-Ovation R

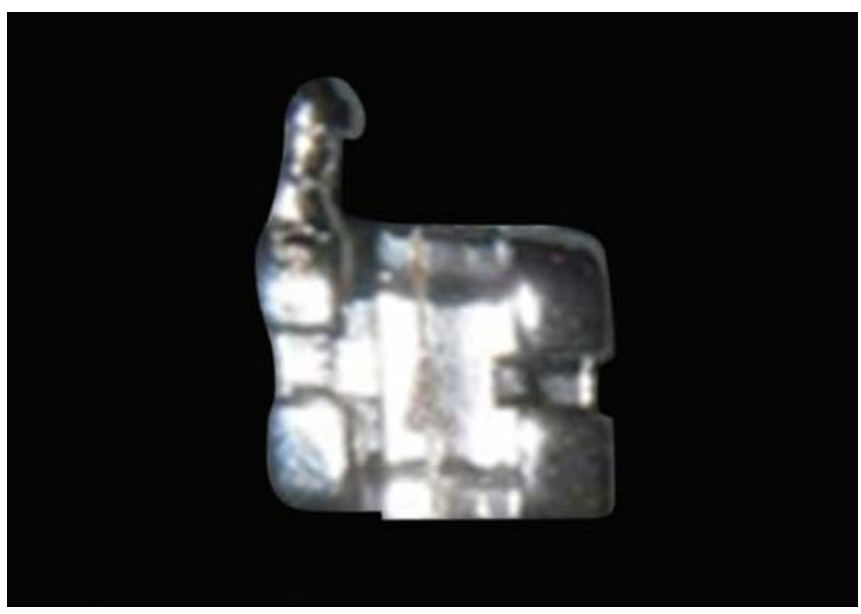

Fig. 5: Rematitan

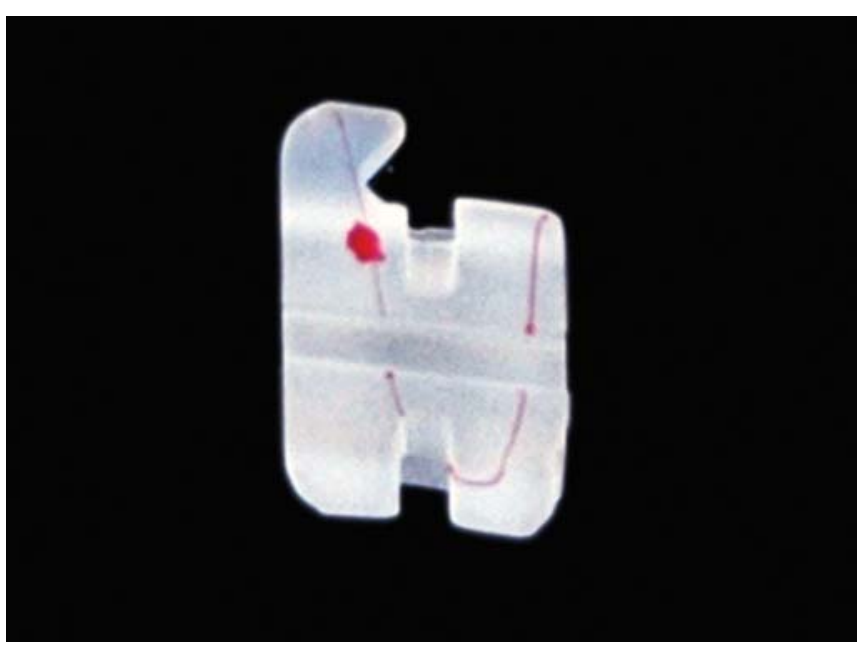

Fig. 6: DB fiberglass

A $19 \times 25$ SS wire was chosen as this is the usual working wire in cases of retraction in $0.022 "$ slot.

A total of 200 samples were tested. Specimens were divided into two categories which were run under dry and wet conditions, using artificial saliva. Around 10 samples of each active and passive self-ligating brackets were dry run and 10 others were used in wet conditions.

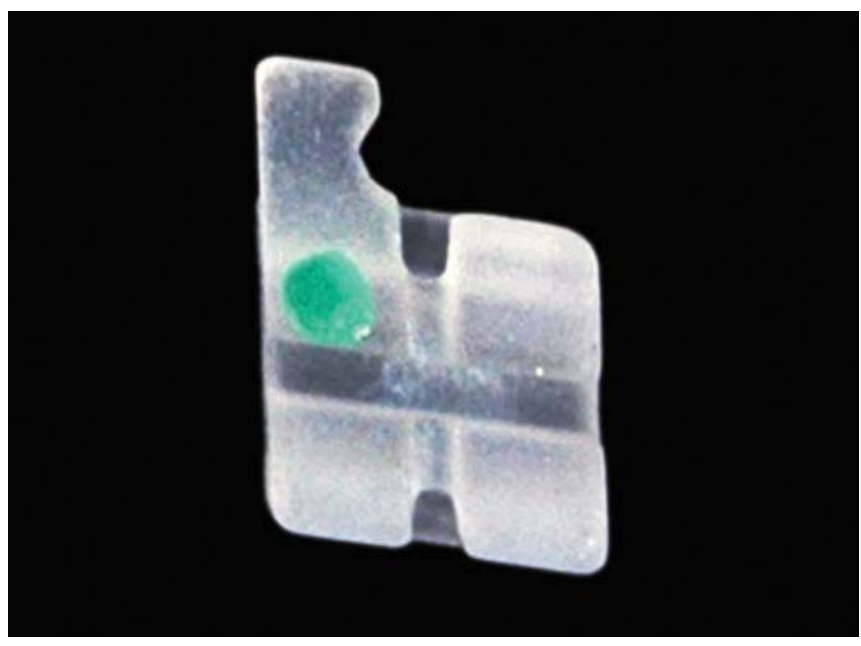

Fig. 7: Fascination (ceramic)

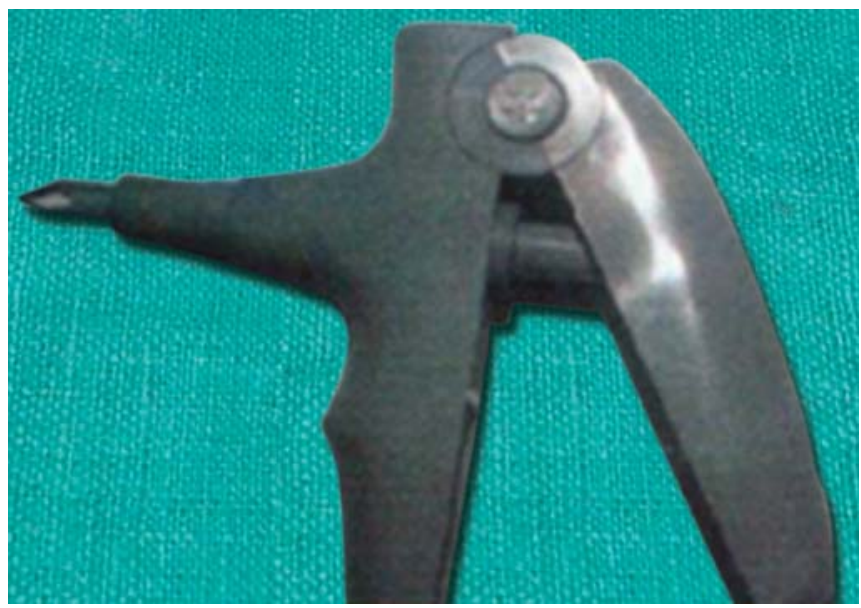

Fig. 8: Straight shooter

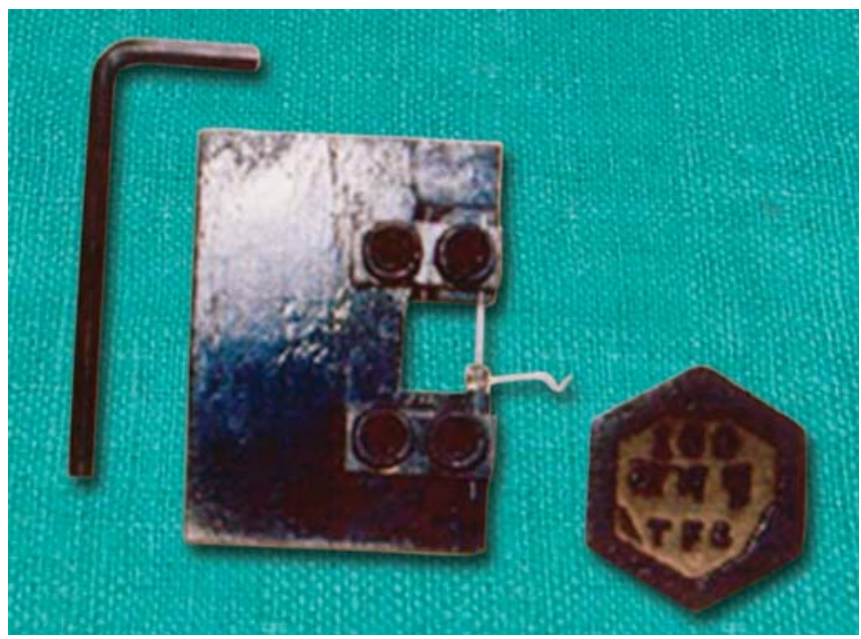

Fig. 9: Modified Tidy’s jig

Around 10 samples of ceramic, titanium and fiberglass brackets were run using elastomeric ties and stainless steel ligatures under dry and wet conditions.

A total of 200 samples were tested of which 80 were selfligating and 120 were conventional brackets.

Elastomeric modules were ligated using elastomeric gun to eliminate stretching differences. 

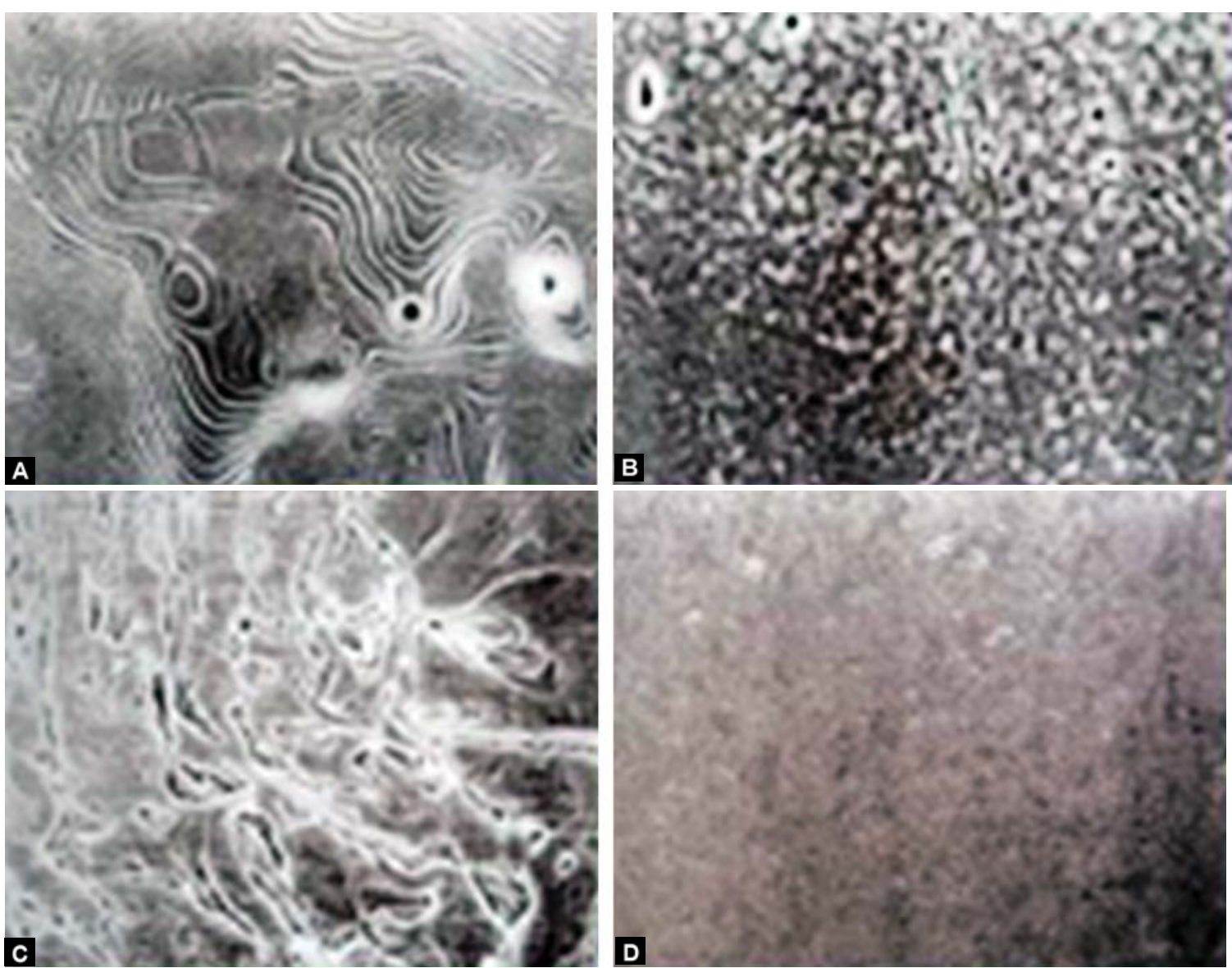

Figs 10A to D: Sem of bracket slots at $\times 500$ : (A) Stainless steel, (B) ceramic, (C) fiberglass, (D) titanium

The steel ligature on the movable bracket was fully tightened till it doubled back and then slightly slackened to allow the bracket to slide freely.

To avoid bias due to repeated use, tests were done each time with a fresh assembly. Tests were done on a universal testing machine (Lloyd model LR-100R, England).

The jig was fixed to the lower member of universal testing machine and upper member was connected to load cell of 100 Newton.

The suspended movable bracket was adjusted to move upward along with the bracket and suspended weight at a constant speed of $5 \mathrm{~mm} / \mathrm{min}$ and the frictional values were recorded.

The testing machine was adjusted such that the weight suspended at the power arm was nullified and load cell readings represented the maximum frictional force required to move the bracket along the archwire for a distance of $5 \mathrm{~mm} / \mathrm{min}$.

Readings were recorded in Newton and were converted to grams (1 N = $101.97 \mathrm{gm})$.

Saliva was dropped onto bracket-wire junction at rate of $1 \mathrm{drop} / \mathrm{mm}$ with the help of a syringe.

Readings in both dry and wet conditions were charted separately.

\section{RESULTS}

To evaluate the results statistically, the following analyses were done.
1. Paired t-test (Table 1)

2. Two sample t-test (Table 2)

3. Anova (Table 3)

- Around 10 samples of each bracket type were tested under dry and 10 each in wet condition

- A total of 80 self-ligating brackets were tested

- $\quad$ Paired t-test for active and passive self-ligating brackets revealed that frictional resistance values were not significant for each bracket type under dry and wet conditions except in In-Ovation $\mathrm{R}$ where the values were significant at 0.05 and nonsignificant at 0.01

- For titanium brackets, the values were not significant, whereas for fiberglass and ceramic the values were significant

- Around 10 samples each were tested under dry and other 10 under wet conditions with elastomeric and stainless steel ligatures. A total of 120 samples were tested

- But when active and passive self-ligating brackets were compared under dry and wet conditions, the values were statistically significant.

Further, Duncan's multiple range test was conducted and was found that all the pairs were statistically different.

\section{DISCUSSION}

Friction is a function of relative roughness of two surfaces in contact and is defined as the resistance to motion encountered when one solid body slides/tends to slide over another. ${ }^{5}$ 
Table 1: Paired t-test

\begin{tabular}{|c|c|c|c|c|}
\hline \multicolumn{5}{|c|}{ Paired t-test } \\
\hline & $\begin{array}{l}\text { Dry } \\
\text { Mean } \pm S D\end{array}$ & $\begin{array}{l}\text { Wet } \\
\text { Mean } \pm S D\end{array}$ & $p$-value & Comments \\
\hline Damon SL-II & $46.01 \pm 2.93$ & $47.4 \pm 3.87$ & 0.229 & NS \\
\hline Smart clip & $62.3 \pm 6.09$ & $66.38 \pm 7.39$ & 0.172 & NS \\
\hline Time-II & $74.21 \pm 7.46$ & $73.33 \pm 5.93$ & 0.474 & NS \\
\hline In-Ovation R & $85.73 \pm 2.63$ & $88.43 \pm 0.81$ & 0.015 & Sig (at 0.05) and NS (at 0.01) \\
\hline Passive & $108.31 \pm 7.78$ & $113.78 \pm 3.29$ & 0.156 & NS \\
\hline Active & $159.95 \pm 8.31$ & $161.75 \pm 5.73$ & 0.318 & NS \\
\hline
\end{tabular}

Table 2: Two-sample t-test

$\begin{array}{lllll} & \begin{array}{l}\text { Dry } \\ \text { Mean } \pm \text { SD }\end{array} & \begin{array}{l}\text { Wet } \\ \text { Mean } \pm \text { SD }\end{array} & \text { p-value } & \text { Comments } \\ \text { Titanium-L } & 100.62 \pm 4.24 & 103.44 \pm 3.89 & 0.138 & \text { NS } \\ \text { Titanium-E } & 113.74 \pm 4.88 & 115.75 \pm 4.26 & 0.342 & \text { NS } \\ \text { Fiberglass-L } & 194.97 \pm 10.33 & 209.23 \pm 8.53 & 0.003 & \text { Sig } \\ \text { Fiberglass-E } & 219.14 \pm 8.59 & 240.74 \pm 10.01 & \text { Sig } \\ \text { Ceramic-L } & 286.65 \pm 15.02 & 303.74 \pm 6.68 & 0.000 & \text { Sig } \\ \text { Ceramic-E } & 313.74 \pm 6.14 & 334.55 \pm 7.49 & 0.004 & \text { Sig } \\ & \text { Active } & \text { Passive } & 0.000 & \text { Comments } \\ \text { Dry } & 159.94 \pm 8.31 & \text { Mean } \pm \text { SD } & & \text { Sig } \\ \text { Wet } & 161.75 \pm 5.73 & 108.31 \pm 7.78 & 0.000 & \text { Sig }\end{array}$

NS: Not significant; Sig: Significant

Table 3: ANOVA

\begin{tabular}{|c|c|c|c|c|c|}
\hline & Sum of squares & $D f$ & Mean square & $F$ & Sig. \\
\hline \multicolumn{6}{|l|}{ Dry } \\
\hline Between groups & 380136.918 & 5 & 76027.384 & 939.337 & 0.000 \\
\hline Within groups & 4370.615 & 54 & 80.937 & & \\
\hline Total & 384507.533 & 59 & & & \\
\hline \multicolumn{6}{|l|}{ Wet } \\
\hline Between groups & 451069.181 & 5 & 90213.836 & 1762.179 & 0.000 \\
\hline Within groups & 2764.502 & 54 & 51.194 & & \\
\hline Total & 453833.683 & 59 & & & \\
\hline
\end{tabular}

One way anova was conducted to see whether samples differ significantly in their mean differences and Duncan's multiple range test revealed that the mean differences obtained for each pair both in wet and dry conditions were significant (alpha $=0.5$ )

Friction exists in two forms as follows:

- Static friction

- Kinetic friction.

Static friction is force needed to start the motion of solid surfaces that were previously at rest with respect to each other. ${ }^{5,6}$

Kinetic friction is the force that resists the sliding motion of one solid object over another at a constant speed. ${ }^{6}$

The coefficient of static friction is always greater than that of kinetic friction. ${ }^{7}$

In orthodontic sliding mechanics, the magnitude of friction is mainly determined by bracket archwire type and material and mode of ligation. ${ }^{7}$
Friction is a factor in all forms of sliding mechanics, such as canine retraction into extraction site and in levelling and alignment where wire must slide through brackets and tubes.

In orthodontic sliding mechanics, mesiodistal tooth movement is accomplished by guiding a tooth along a continuous archwire with the use of orthodontic brackets. This type of tooth movement generates frictional forces that must be overcome to elicit periodontal response for the tooth movement. ${ }^{8}$

Rate of tooth movement during orthodontic treatment is dependent on a number of mechanical and biological variables. 9,10

These variables can directly or indirectly contribute to frictional force levels between brackets and archwires. 


\section{MECHANICAL}

1. Archwire
a. Material $^{11,12}$
b. Cross-sectional shape/size $\mathrm{e}^{11,13}$
c. Surface texture ${ }^{12}$
d. Stiffness $^{12}$

2. Ligation of archwire to the bracket
a. Ligature wire ${ }^{13,14}$
b. Elastomeric ${ }^{13,14}$

3. Bracket
a. Material $^{13,14}$
b. Slot width and depth ${ }^{13,14}$
c. First-order bends (in-out) $)^{13,14}$
d. Second-order bends (angulations) ${ }^{13,14}$
e. Third-order bends (torque) ${ }^{13,14}$

4. Orthodontic appliance
a. Interbracket distance ${ }^{13}$
b. Level of slot $b / n$ adjacent teeth ${ }^{13}$
c. Forces applied for retraction ${ }^{13}$

5. Intraoral biological variable
a. Saliva ${ }^{14}$
b. Plaque and acquired pellicle ${ }^{14}$
c. Corrosion. $^{14}$

In the present study, the passive self-ligating brackets showed least frictional resistance followed by active self-ligating brackets.

This difference is due to differences in the bracket design. In active self-ligating brackets, the spring-clip presses against the archwire to secure it in the bracket slot. The primary objective of active self-ligation is to seat the archwire against the back of the slot for torque and rotational control. This results in reduction of slot size in passive state increasing the level of friction. In passive self-ligating bracket when the fourth wall is closed it converts into a tube, where the lumen of the bracket remains at full size, thus generating lesser friction. ${ }^{15-17}$

In passive self-ligating brackets damon SL-2 showed lesser friction than smart clip. The reason may be difference in the fourth wall where in damon SL-2 the complete width of slot is covered by fourth wall making it as a tube, whereas in smart clip only the mesial and distal ends are covered by closing clips leaving the slot open.

In active self-ligating brackets time-2 showed lesser friction compared to inovation $\mathrm{R}$. The difference may be due to spring clip designs that press against the archwire in the slot.

In general, among conventional bracket systems titanium brackets showed least friction followed by fiberglass and ceramic brackets. This may be due to difference in surface roughness of the material and presence of titanium oxide layer on brackets which render the surface chemically passive, and promote excellent sliding mechanics with lower frictional force. ${ }^{18}$ The greater friction of ceramic bracket is most likely related to surface roughness of the slot and hardness of the material.

In general, among conventional bracket system friction was greater in elastomeric compared to stainless steel ligation and self-ligating brackets had least friction. ${ }^{19}$
Friction is contributed by chemical structure, structural integrity and mechanical properties, which is largely due to the atomic and molecular forces of attraction at small contacts areas $\mathrm{b} / \mathrm{n}$ materials.

When a single bracket is tested under dry and wet conditions, the role of saliva was not significant, whereas when compared with bracket groups, the result was significant, i.e. with saliva the frictional resistance encountered was more when compared to dry run samples. ${ }^{20}$

\section{CONCLUSION}

The self-ligating brackets seem to be promising in quenching the thirst of orthodontist to have a bracket that is functionally efficient with reduced friction, esthetically pleasing, reduced treatment and chairside time, combined with better oral hygiene maintenance and patient comfort because of absence of ligation.

Self-ligating brackets made of titanium may prove to be more efficient than stainless steel due to its superior structural integrity and surface smoothness compared with stainless steel.

Recently, ceramic self-ligating brackets have been introduced by Gac (In-Ovation C). Further studies may be conducted using these newer brackets.

\section{ACKNOWLEDGMENTS}

We like to extend our special thanks to all our faculty members and postgraduate students of Department of Orthodontics and Dentofacial Orthopedics, JSS Dental College and Hospital, Mysore, Karnataka, India, for their valuable advice and support during the study. We also like to thank Mr Arvind of CIPET (Central Institute of Plastics and Engineering Technology). And also to statistician Ms Vidya for her sincere assistance in analysing our data statistically.

\section{REFERENCES}

1. Garner LD, et al. A comparison of frictional forces during simulated canine retraction of a continuous edgewise archwire. Am J Orthod Dentofac Orthop 1986;90:199-203.

2. Kapur R, et al. Comparison of frictional resistance in titanium and stainless steel brackets. Am J Orthod Dentofac Orthop 1999;116:271-74.

3. Kapur R, Sinha PK, Nanda RS. Comparison of load transmission and bracket deformation between titanium and stainless steel brackets. Am J Orthod Dentofac Orthop 1999;116:275-78.

4. Pratten DR, et al. Frictional resistance of ceramic and stainless steel orthodontic brackets. Am J Orthod Dentofac Orthop 1990;98:398-403.

5. Tselepsis M, Broskhurst P, West VC. The dynamic frictional resistance between orthodontic brackets and archwires. Am J Orthod Dentofac Orthop 1994;106:131-38.

6. Omana HM, Moore RN, Bagby MD. Frictional properties of metal and ceramic brackets. J Clin Orthod 1992;26:425-32. 
7. Bednar JR, Greendeman GN, Sandrick JC. A comparative study of frictional force between orthodontic brackets and archwires. Am J Orthod Dentofac Orthop 1991;100:513-22.

8. Ogata RH, Nanda RS, et al. Frictional resistance in stainless steel bracket-wire combinations with effect of vertical deflections. Am J Orthod Dentofac Orthop 1996;109:535-42.

9. Downing A, et al. A study of frictional forces between orthodontic brackets and archwires. Br J Orthod 1994;21: 349-57.

10. Vaughan JC, et al. Relative kinetic frictional forces between sintered stainless steel brackets and orthodontic wires. Am J Orthod Dentofac Orthop 1995;107:20-27.

11. Angolkar PV, et al. Evaluation of friction between ceramic brackets and orthodontic wires of four alloys. Am J Orthod Dentofac Orthop 1990;98:499-506.

12. Drescher, et al. Frictional forces between bracket and archwires. Am J Orthod Dentofac Orthop 1989;96:397-404.

13. Frank CA, Nikoalai RJ. A comparative study of frictional resistance between orthodontic bracket and archwire. Am J Orthod Dentofac Orthop 1980;78:593-609.
14. Riley JC, et al. Frictional forces of ligated plastic and metal edgewise brackets. J Dent Res 1989;58:A-21 Abstracts.

15. Damon DH. The rationale. Evolution and clinical application of the self- ligating bracket. Clin Orthod Res 1998;1:52-61.

16. Damon DH. The Damon low friction bracket. A biologically compatible straight system. J Clin Orthod 1998;22:670-79.

17. Damon DH. Introducing the Damon system-2 Clin Impressions 1999;8:2-9,31.

18. Kusy RP, et al. Comparison of the frictional coefficient for selected archwire bracket slot combinations in dry and wet states. Angle Orthod 1991;61:293-301.

19. Thomas S, et al. A comparative in vitro study of the frictional characteristics of two types of self-ligating brackets and two types of preadjusted edgewise brackets tied with elastomeric ligatures. Eur J Orthod 1998;20:589-96.

20. Stannard JG, et al. Comparative study of orthodontic wires under dry and wet conditions. Am J Orthod Dentofac Orthop 1986;89:485-91. 